\title{
25 Research Square \\ Reference values of fat mass index and fat-free mass index in healthy Spanish adolescents.
}

\section{Teodoro Durá-Travé ( $\nabla$ tduratra@cfnavarra.es )}

Universidad de Navarra https://orcid.org/0000-0002-4628-2213

\section{Fidel Gallinas-Victoriano}

Complejo Hospitalario de Navarra

\section{María Chueca-Guindulain}

Complejo Hospitalario de Navarra

\section{Sara Berrade-Zubiri}

Complejo Hospitalario de Navarra

\section{María Malumbres-Chacón}

Complejo Hospitalario de Navarra

Paula Moreno-González

Complejo Hospitalario de Navarra

\section{Research article}

Keywords: Adolescents, Anthropometric measurements, Body composition, Fat mass index, Fat free mass index, Skinfold thickness

Posted Date: December 2nd, 2019

DOI: https://doi.org/10.21203/rs.2.17933/v1

License: (c) (i) This work is licensed under a Creative Commons Attribution 4.0 International License. Read Full License

Version of Record: A version of this preprint was published at Nutrición Hospitalaria on January 1st, 2020. See the published version at https://doi.org/10.20960/nh.03161. 


\section{Abstract}

Background. Body mass index (BMI) does not allow to discriminate the composition of the different body compartments. The aim of this study is to elaborate reference values of the fat mass index (FMI) and fatfree mass index (FFMI) in healthy adolescents using anthropometric techniques in order to be available as reference standards in daily clinical practice.

Methods. Transversal study in 940 healthy Caucasian adolescents (370 males and 570 females), aged 10.1 to 14.9 years. Weight, height and skinfold thickness were registered, and BMI, percentage of total boy fat, FMI and FFMI, and FMI and FFMI percentiles were calculated.

Results. In males a significant increase in the FFMI is observed, and the percentage of total body fat and FMI significantly decreased. In contrast, in females the percentage of body fat mass, FMI and FFMI significantly increased. Except for the 10 years, FMI was higher $(p<0.05)$ in females in all ages. FFMI was higher $(p<0.05)$ in males in all ages. FFMI and FMI percentiles for healthy adolescents (both sexes) categorized by age are displayed.

Conclusions. Reference values of FMI and FFMI would be a very useful instrument for the diagnosis and analysis of body composition changes during the treatment of childhood obesity.

\section{Background}

Obesity is characterised by an excess of body fat, being body mass index (BMI) the most usual anthropometric measurement for nutritional assessment in daily clinical practice. As a consequence, it is widely used for the diagnosis of childhood obesity [1]. However, BMI does not allow to discriminate the proportional composition of the different body compartments: fat mass and fat-free mass [2-5]. In fact, several authors advocate in the use of the fat mass index (FMI) in contrast to the BMI in order to diagnose and monitor childhood obesity, owing to the higher sensibility to detect changes in body fat [69].

The use of FMI in the diagnosis and monitoring of childhood obesity is not sufficiently widespread, and there are few referent charts for pediatricians $[10,11]$. At present, the anthropometric evaluation, due to its simplicity and low cost, is considered an important step in the monitoring of body composition in the pediatric age and should occupy a prominent place in this process $[7,11-15]$. In point of fact, it would be very useful to arrange for reference charts of FMI as well as fat-free mass index (FFMI) based on the measurements of body skin folds.

The aim of the present work is to compile standard values charts for FMI and FFMI in healthy adolescents (both sexes), from the measurement of skin folds in order to be available as benchmarks in daily clinical practice. 


\section{Materials And Methods}

\section{Participants}

Anthropometric data were collected from a randomly selected group of 940 healthy Caucasian adolescents (370 males and 570 females), aged 10.1 to 14.9 years, who were selected from four public school centers located in the city of Pamplona (Navarre, Spain) in the period January-June 2018. The normality of the nutrition status was the condition sine qua non to be included in this study; this means, BMI should range between +1 and -1 standard deviations (Z-score).

\section{Anthropometric measurements}

The following anthropometric measurements were registered: weight, height, body mass index (BMI) and skinfold thickness (biceps, triceps, subscapular and suprailiac).

Weight and height measurements were taken with participants in underwear and barefoot. An Año-Sayol scale was used for weight measurement (reading interval 0 to $120 \mathrm{~kg}$ and a precision of $100 \mathrm{~g}$ ), and a Holtain wall stadiometer for height measurement (reading interval 60 to $210 \mathrm{~cm}$, precision $0.1 \mathrm{~cm}$ ). BMI was calculated according to the following formula: weight $(\mathrm{kg}) /$ height $^{2}(\mathrm{~m})$.

Skinfold-thickness measurements were performed in triplicate at the biceps, triceps, subscapular, and suprailiac sites, and the mean of the 3 values was used, and measurements were performed by the same trained individual. Skinfold thicknesses values were measured to a precision of $0.1 \mathrm{~mm}$ on the left side of the body with Holtain skinfold calipers (CMS Weighing Equipment, Crymych, United Kingdom). The percentage of total body fat, fat mass $(\mathrm{kg})$ and fat-free mass $(\mathrm{kg})$ were calculated using the equations reported by Slaughter et al. [16], adjusted for sex and age. In the same way, the fat mass index (FMI) and the fat free mass index (FFMI) were estimated using the following formulas: fat mass $(\mathrm{kg}) /$ height $^{2}(\mathrm{~m})$, and free fat mass $(\mathrm{kg}) /$ height $^{2}(\mathrm{~m})$, respectively.

The z-score values for the BMI were computed using the program Aplicación Nutricional, from the Spanish Society of pediatric gastroenterology, hepatology and nutrition (Sociedad Española de Gastroenterología, Hepatología y Nutrición Pediátrica, available at http://www.gastroinf.es/nutritional/). The graphics from Ferrández et al. (Centro Andrea Prader, Zaragoza 2002) were used as reference charts [17].

\section{Statistical analysis}

Results are displayed as means (M) with corresponding standard deviations (SDs). The statistical analysis (descriptive statistics, percentiles calculation, Student's $t$ test, and analysis of variance) was executed using the program Statistical Packages for the Social Sciences version 20.0 (SPSS, Chicago, IL, USA). The condition for statistical significance was a P-value $<0.05$. 
Parents and/or legal guardians were informed and provided consent for the participation in this study in all cases. This study was approved by the Ethics Committee for Human Investigation of Navarra Hospital Complex (in accordance with the ethical standards laid down in the 1964 Declaration of Helsinki and later amendments).

\section{Results}

Table 1 lists and compares the mean values of anthropometric and body composition characteristics according to age in adolescents males. A significant increase in the mean values of weigh, height, BMI, fat-mass, fat free-mas and FFMI is observed $(P<0.05)$. In contrast, mean values of body fat, skinfold thickness (triceps) and FMI significantly decreased $(P<0.05)$. There are no significant differences in mean values of BMI z-score and skinfold thickness (biceps, subscapular and suprailiac).

Table 1. Anthropometric measurements and body composition in adolescent males (M + DS).

\begin{tabular}{lllllll} 
& $10 \mathrm{y}$ & $11 \mathrm{y}$ & $12 \mathrm{y}$ & $13 \mathrm{y}$ & $14 \mathrm{y}$ & P-value $^{*}$ \\
& $(\mathrm{n}=62)$ & $(\mathrm{n}=64)$ & $(\mathrm{n}=92)$ & $(\mathrm{n}=88)$ & $(\mathrm{n}=64)$ & \\
\hline Age $(\mathrm{y})$ & $10.4 \pm 0.3$ & $11.5 \pm 0.2$ & $12.4 \pm 0.2$ & $13.4 \pm 0.2$ & $14.2 \pm .1$ & 0.001 \\
Weight $(\mathrm{kg})$ & $37.9 \pm 6.1$ & $39.8 \pm 5.5$ & $43.2 \pm 7.6$ & $49.3 \pm 7.8$ & $54.1 \pm 9.1$ & 0.001 \\
Height $(\mathrm{cm})$ & $142 \pm 9.7$ & $146.5 \pm 8.2$ & $153.4 \pm 9.5$ & $158.7 \pm 9.6$ & $164.8 \pm 9.4$ & 0.001 \\
BMI (Kg/m $\left.{ }^{2}\right)$ & $18.7 \pm 1.5$ & $18.9 \pm 1.5$ & $19.2 \pm 1.5$ & $19.6 \pm 1.6$ & $20.3 \pm 1.7$ & 0.001 \\
BMI z-score & $0.08 \pm 0.61$ & $0.02 \pm 0.56$ & $0.01 \pm 0.54$ & $0.05 \pm 0.57$ & $0.05 \pm 0.05$ & 0.072 \\
Skinfold thickness & & & & & & \\
Biceps (cm) & $9.1 \pm 3.5$ & $8.9 \pm 2.9$ & $9.1 \pm 3.8$ & $8.3 \pm 4.2$ & $8.9 \pm 4.1$ & 0.508 \\
Triceps (cm) & $14.2 \pm 3.7$ & $14.5 \pm 4.1$ & $13.9 \pm 5.1$ & $13.4 \pm 5.2$ & $13.5 \pm 4.9$ & 0.028 \\
Subscapular (cm) & $9.9 \pm 4.1$ & $9.8 \pm 4.3$ & $10.3 \pm 5.1$ & $10.2 \pm 5.3$ & $10.2 \pm 3.9$ & 0.222 \\
Suprailiac (cm) & $12.3 \pm 6.3$ & $12.4 \pm 6.5$ & $12.2 \pm 6.1$ & $12.6 \pm 6.8$ & $12.4 \pm 6.4$ & 0.328 \\
& & & & & & \\
Body fat (\%) & $25.4 \pm 5.8$ & $24.4 \pm 4.5$ & $23.1 \pm 5.9$ & $21.5 \pm 5.9$ & $22.4 \pm 5.9$ & 0.001 \\
Fat mass (kg) & $9.7 \pm 3.1$ & $9.7 \pm 2.9$ & $10.1 \pm 3.8$ & $10.2 \pm 3.7$ & $11.9 \pm 4.1$ & 0.001 \\
Fat-free mass $(\mathrm{kg})$ & $28.2 \pm 4.3$ & $28.7 \pm 4.1$ & $32.7 \pm 5.6$ & $37.1 \pm 5.8$ & $39.8 \pm 6.1$ & 0.001 \\
FMl (kg/m $\left.{ }^{2}\right)$ & $4.8 \pm 1.4$ & $4.6 \pm 1.2$ & $4.4 \pm 1.4$ & $4.2 \pm 1.4$ & $4.3 \pm 1.5$ & 0.003 \\
FFMl (kg/m $\left.{ }^{2}\right)$ & $13.8 \pm 0.7$ & $14.2 \pm 0.9$ & $14.7 \pm 0.9$ & $15.3 \pm 0.9$ & $15.6 \pm 0.7$ & 0.001 \\
& & & & & &
\end{tabular}

(*) ANOVA. BMI: body mass index. FMI: fat mass index. FFMI: fat-free mass index 
Table 2 displays the percentiles distributions of FFMI and FMI of adolescents male categorized by age. Table 2. Percentiles values for fat mass index and fat-free mass index in adolescent males in different ages.

\begin{tabular}{|llllllll}
\multicolumn{7}{l}{ Fat mass index $\left(\mathrm{kg} / \mathrm{m}^{2}\right)$} \\
\hline Age & P 3 & P 10 & P 25 & P 50 & P 75 & P 90 & P 97 \\
\hline 10 y & 2.78 & 2.85 & 3.79 & 4.29 & 6.25 & 7.32 & 7.45 \\
11 y & 2.47 & 2.86 & 3.58 & 4.22 & 5.91 & 6.93 & 7.45 \\
12 y & 2.17 & 2.90 & 3.38 & 4.15 & 5.57 & 6.54 & 7.46 \\
13 y & 2.15 & 2.48 & 3.09 & 4.10 & 5.56 & 6.52 & 6.81 \\
14 y & 2.21 & 2.38 & 3.07 & 4.61 & 5.82 & 6.76 & 6.95 \\
\hline
\end{tabular}

Fat-free mass index $\left(\mathrm{kg} / \mathrm{m}^{2}\right)$

\begin{tabular}{llllllll}
\hline Age & P 3 & P 10 & P 25 & P 50 & P 75 & P 90 & P97 \\
\hline 10 y & 12.25 & 12.90 & 13.45 & 13.93 & 14.28 & 14.8 & 15.12 \\
11 y & 12.75 & 13.10 & 13.74 & 14.39 & 14.86 & 15.57 & 15.85 \\
12 y & 13.28 & 13.33 & 13.96 & 14.84 & 15.41 & 16.35 & 16.61 \\
13 y & 13.38 & 14.27 & 14.61 & 15.32 & 15.81 & 17.11 & 17.85 \\
14 y & 14.35 & 14.81 & 15.31 & 15.51 & 16.17 & 16.91 & 17.44
\end{tabular}

P: Percentil

Table 3 shows and compares the mean values of anthropometric and body composition characteristics related to age group in adolescents females. Mean values of weigh, height, BMl, skinfold thickness (subescapular and suprailiac), body fat, fat-mass, fat free-mas, FMI and FFMI significantly increased $(P<0.05)$. No significant differences in mean values of BMI $z$-score and skinfold thickness (biceps and triceps) were detected.

Table 3. Anthropometric measurements and body composition in adolescent females (M+DS). 


\begin{tabular}{|c|c|c|c|c|c|c|}
\hline & $\begin{array}{l}10 y \\
(n=148)\end{array}$ & $\begin{array}{l}11 y \\
(n=108)\end{array}$ & $\begin{array}{l}12 y \\
(n=110)\end{array}$ & $\begin{array}{l}13 y \\
(n=104)\end{array}$ & $\begin{array}{l}14 y \\
(n=100)\end{array}$ & P-value* \\
\hline Age (y) & $10.4 \pm 0.2$ & $11.5 \pm 0.3$ & $12.4 \pm 0.3$ & $13.4 \pm .2$ & $14.3 \pm 0.2$ & 0.001 \\
\hline Weight (kg) & $38.1 \pm 5.3$ & $42.8 \pm 6.4$ & $46.0 \pm 6.7$ & $49 \pm 6.9$ & $52.2 \pm 8.1$ & 0.001 \\
\hline Height (cm) & $143 \pm 7.3$ & $149 \pm 8.6$ & $154.1 \pm 8.5$ & $157.7 \pm 8.2$ & $159.8 \pm 7.1$ & 0.001 \\
\hline $\mathrm{BMI}\left(\mathrm{Kg} / \mathrm{m}^{2}\right)$ & $18.6 \pm 1.4$ & $19.3 \pm 1.6$ & $19.7 \pm 1.9$ & $20.1 \pm 1.7$ & $20.8 \pm 1.9$ & 0.001 \\
\hline BMI z-score & $0.09 \pm 0,5$ & $0.09 \pm 0,53$ & $0.04 \pm 0,64$ & $0.05 \pm 0,57$ & $0.02 \pm 0,67$ & 0.086 \\
\hline \multicolumn{7}{|l|}{ Skinfold thickness } \\
\hline Biceps (cm) & $10.3 \pm 3.4$ & $10.3 \pm 3.9$ & $10.1 \pm 2.8$ & $10.4 \pm 3.3$ & $10.9 \pm 3.2$ & 0.709 \\
\hline Triceps (cm) & $16.1 \pm 3.9$ & $15.8 \pm 4.4$ & $15.9 \pm 4.4$ & $16.3 \pm 4.5$ & $16.9 \pm 3.7$ & 0.738 \\
\hline Subscapular (cm) & $10.9 \pm 4.2$ & $11.4 \pm 4.8$ & $11.1 \pm 4.1$ & $12.2 \pm 5.2$ & $13.1 \pm 5.1$ & 0.002 \\
\hline Suprailiac (cm) & $14.4 \pm 6.1$ & $15.7 \pm 6.5$ & $15.9 \pm 6.5$ & $17.7 \pm 7.1$ & $18.2 \pm 6.4$ & 0.001 \\
\hline Body fat (\%) & $27.4 \pm 5.9$ & $28.3 \pm 4.3$ & $28.6 \pm 3.7$ & $29.2 \pm 4.2$ & $29.3 \pm 3.5$ & 0.005 \\
\hline Fat mass $(\mathrm{kg})$ & $10.7+3.3$ & $12.5 \pm 3.0$ & $13.0 \pm 3.1$ & $14.3 \pm 2.8$ & $15.6 \pm 3.8$ & 0.001 \\
\hline Fat-free mass (kg) & $27.7 \pm 3.2$ & $31.3 \pm 4.4$ & $33.7 \pm 4.4$ & $34.7 \pm 4.3$ & $37.0 \pm 4.4$ & 0.001 \\
\hline $\mathrm{FMI}\left(\mathrm{kg} / \mathrm{m}^{2}\right)$ & $5.1 \pm 1.4$ & $5.5 \pm 1.2$ & $5.7 \pm 1.1$ & $5.9 \pm 1.2$ & $6.2 \pm 1.2$ & 0.001 \\
\hline FFMI $\left(\mathrm{kg} / \mathrm{m}^{2}\right)$ & $13.4 \pm 0.8$ & $13.8 \pm 0.8$ & $14.2 \pm 0.9$ & $14.3 \pm 0.9$ & $14.7 \pm 0.9$ & 0.001 \\
\hline
\end{tabular}

(*) ANOVA. BMI: body mass index. FMl: fat mass index. FFMI: fat-free mass index.

Table 4 displays the percentiles distributions of FFMI and FMI for female adolescents categorized by age.

Table 4. Percentiles values for fat mass index and fat-free mass index in adolescent females in different ages. 


\begin{tabular}{llllllll}
\multicolumn{7}{c}{ Fat mass index $\left(\mathrm{kg} / \mathrm{m}^{2}\right)$} \\
\hline Age & P 3 & P 10 & P 25 & P 50 & P 75 & P 90 & P 97 \\
\hline 10 y & 2.79 & 3.46 & 3.92 & 5.33 & 6.24 & 7.31 & 7.74 \\
11 y & 3.57 & 3.77 & 4.68 & 5.49 & 6.30 & 7.21 & 7.89 \\
12 y & 3.75 & 4.12 & 4.68 & 5.18 & 6.40 & 7.33 & 7.88 \\
13 y & 3.89 & 3.99 & 4.83 & 5.91 & 7.07 & 7.79 & 7.90 \\
14 y & 4.08 & 4.80 & 5.02 & 6.46 & 6.99 & 8.28 & 8.60 \\
\hline
\end{tabular}

\begin{tabular}{|llllllll}
\multicolumn{7}{l}{ Fat-free mass index $\left(\mathrm{kg} / \mathrm{m}^{2}\right)$} \\
\hline Age & P 3 & P 10 & P 25 & P 50 & P 75 & P 90 & P 97 \\
\hline 10 y & 12.05 & 12.31 & 12.84 & 13.54 & 14.04 & 14.53 & 14.91 \\
11 y & 12.48 & 12.79 & 13.17 & 13.87 & 14.39 & 14.86 & 15.52 \\
12 y & 12.86 & 13.04 & 13.54 & 14.29 & 15.07 & 15.76 & 16.31 \\
13 y & 12.77 & 12.78 & 13.62 & 14.21 & 14.45 & 16.12 & 16.35 \\
14 y & 12.84 & 13.00 & 13.87 & 14.88 & 15.61 & 16.00 & 16.55
\end{tabular}

P: percentil

Figure 1 lists and presents a comparison of average values for FMI in both sexes in the different ages. With the exception of the period 10-11 years, the value of FMI was significantly higher $(p<0.05)$ in females with respect to males in all ages.

Figure 2 shows and contrasts the mean values for FFMI in both sexes in the different ages. FFMI was significantly higher $(p<0.05)$ in males in all ages.

The comparison of mean values for BMI in both sexes in all ages shows no significant differences.

\section{Discussion}

The analysis of the evolutionary changes in the body compartments (fat mass and fat-free mas) in healthy adolescents -between 10 and 14 years of ages- with a normal BMI adjusted for age and sex reveals a different pattern in relation to sex. There is a progressive and significant increase in the FFMI in both sexes, and males show significantly higher values than females; in addition, there is a progressive and significant decrease in the FMI in males, in contrast to the progressive and significant increase in the FMI in females. It should be stressed that these changes take place simultaneously with a progressive 
increase in BMI in both sexes in this period of life, in the absence of significant differences of BMI values in both sexes in the different ages considered.

In this study, BMI was applied for the classification of the nutritional status of the children who were included. However, although it may be useful to define overweight and obesity $[1,7,18,19]$, it provides limited information since it denotes excessive weight in relation to height rather than excessive body fat; this means, it does not allow to discriminate the relative composition of the different body compartments: fat mass and fat-free mass $[2-5,20]$. This limitation becomes more evident in adolescence, when a series of physiological changes occur $[21,22]$ and an increase of weight might be erroneously identified as excessive fat accumulation $[23,24]$ Therefore, having in place standardized values of FMI and FFMI in healthy adolescents would allow to distinguish between those individuals that, for example, present with high values of BMI and, simultaneously, show a low FFMI and high FMI (a situation that corresponds with overweight or obesity), and those that also present with high BMI but show high FFMI and low FMI (a situation that would be identified as muscle hypertrophy, which is quite frequent in adolescent males).

Few reference charts of FMI and FFMI in the pediatric age have been published to date, and they are usually based on sophisticated methodologies and poorly accessible in clinical practice, such as bioelectrical impedance analysis, dual -energy X-ray absorptiometry or isotope dilution [10,11, 25]; its use is basically limited to investigation. However, there is ample evidence that the values that have been obtained by using anthropometric measurements correlate extremely well with those collected with these sophisticated and high cost techniques [7, 11-15, 26]; even those more simple models which divide the body in FM and FFM are as valid as those more complex models that subdivide FFM in its different components (water, proteins, minerals) [25].

\section{Conclusions}

As a conclusion, having an easy access to charts (made from the measurements of skin folds) that might be valid as referent patterns in healthy adolescents of both sexes would be a very useful instrument in clinical practice for the diagnosis and, especially, the analysis of body changes that might take place during the treatment of childhood obesity.

\section{Abbreviations}

BMI: body mass index

FFMI: fat-free mass index

FMl: fat mass index

\section{Declarations}

Ethics and approval and consent to participate. 
This study was approved by the Ethics Committee for Human Investigation of the Navarra Hospital Complex, Pamplona, Spain (in accordance with the ethical standards laid down in the 1964 Declaration of Hensinki and later amendments). Parents and/or legal guardians were informed and provided consent for the participation in this study in all cases.

\section{Consent for publication.}

Not applicable

\section{Availability of data and material.}

The datasets used and/or analysed during the current study are available from the corresponding author on reasonable request.

\section{Competing interests.}

The authors declare that they have no competing interests

Funding. The authors received no financial support for the research, authorship, and/or publication of this article (none declared).

Author's contributions. TDT and FGV participated in study design and data analysis, and wrote the first draft of the manuscript. MCG, SBZ, MMC and PMG participated in data collection and analysis. All authors participated in manuscript preparation and approved its final version.

\section{Acknowledgments}

Not applicable

\section{References}

1. Styne DM, Arslanian SA, Connor EL, et al. Pediatric Obesity-Assessment, Treatment, and Prevention: An Endocrine Society Clinical Practice Guideline. J Clin Endocrinol Metab 2017; 102:1-49. 
2. Freedman DS, Wang J, Thornton JC, et al. Classification of body fatness by body mass index-for-age categories among children. Arch Pediatr Adolesc Med. 2009; 163: 805-11.

3. Javed A, Jumean M, Murad MH, et al. Diagnostic performance of body mass index to identify obesity as defined by body adiposity in children and adolescents: a systematic review and meta-analysis. Pediatr Obes. 2015;10:234-44.

4. Mei Z, Grummer-Strawn LM, Pietrobelli A, Goulding A, Goran MI, Dietz WH. Validity of body mass index compared with other body-composition screening indexes for the assessment of body fatness in children and adolescents. Am J Clin Nutr 2002; 75:978-85.

5. Frankenfield DC, Rowe WA, Cooney RN, Smith JS, Becker D. Limits of body mass index to detect obesity and predict body composition. Nutrition 2001; 17:26-30.

6. Schutz Y, Kyle UU, Pichard C. Fat-free mass index and fat mass index percentiles in Caucasians aged 18 e98 y. Int J Obes Relat Metab Disord 2002; 26:953-60.

7. De Miguel-Etayo P, Moreno LA, Santabarbara J, et al. Anthropometric indices to assess body-fat changes during a multidisciplinary obesity treatment in adolescents: EVASYON Study. Clinical Nutrition 2015; 34:523-28.

8. Okorodudu DO, Jumean MF, Montori VM, et al. Diagnostic performance of body mass index to identify obesity as defined by body adiposity: a systematic review and meta-analysis. Int J Obes (Lond). 2010; 34:791-9.

9. Pereira-da-Silva L, Dias MP, Dionísio E, Virella D, Alves M, Diamantino C, et al. Fat mass index performs best in monitoring management of obesity in prepubertal children. $\mathrm{J}$ Pediatr (Rio $\mathrm{J}$ ). 2016;92(4):421-6.

10. Nakao T, Komiya S. Reference norms for a fat-free mass index and fat mass index in the Japanese child population. J Physiol Anthropol Appl Human Sci 2003; 22: 293-8

11. Wells JC, Williams JE, Chomtho S, et al. Body composition reference data for simple and reference techniques and a 4-component model: a new UK reference child. Am J Clin Nutr 2012; 96:1316-26.

12. Weyers AM, Mazzetti SA, Love DM, Gomez AL, Kraemer WJ, Volek JS. Comparison of methods for assessing body composition changes during weight loss. Med Sci Sports Exerc 2002;34:497-502.

13. Elberg J, McDuffie JR, Sebring NG, et al. Comparison of methods to assess change in children's body com-position. Am J Clin Nutr 2004;80:64-9.

14. Sopher AB, Thornton JC, Wang J, Pierson RN, Heymsfield SB, Horlick M. Measurement of percentage of body fat in 411 children and adolescents: A comparison of dual-energy X-ray absorptiometry with a four-compartment model. Pediatrics 2004;113:1285-90.

15. Martin-Calvo N, Moreno-Galarraga L, Martinez-Gonzalez MA. Association between Body Mass Index, Waist-to-Height Ratio and Adiposity in Children: A Systematic Review and Meta-Analysis. Nutrients. 2016; 20: 8(8).

16. Slaughter MH, Lohman TG, Boileau RA, Horswill CA, Stillman RJ, van Loan MD \& Bemben DA (1988): Skinfold equations for estimation of body fatness in children and youths. Hum. Biol. 60, 709-723. 
17. Ferrandez A, Baguer L, Labarta JL, Labena C, Mayayo E, Puba B. Longitudinal pubertad growth according to age at pubertal study of normal Spanish children from birth to adulthood. Pediatr Endocr Rev 2005; 2:423-559.

18. Durá-Travé T, Gallinas-Victoriano F, Urretavizcaya-Martinez M, Ahmed-Mohamed L, Guindulain MJC, Berrade-Zubiri S. Assessment of body composition changes during a combined intervention for the treatment of childhood obesity. Nutrition. 2019; 59:116-20.

19. Alves CAS, Mocellin MC, Andrade Gonçalves EC, Silva DAS, Trindade EBSM. Anthropometric Indicators as Body Fat Discriminators in Children and Adolescents: A Systematic Review and MetaAnalysis. Adv Nutr 2017; 8:718-27.

20. Demerath EW, Schubert CM, Maynard LM, et al. Do changes in body mass index percentile reflect changes in body composition in children? Data from the Fels Longitudinal Study. Pediatrics. 2006; 117(3):e487-95.

21. Odgen CL, Li Y, Freedman DS, Borrud LG, Flegal KM. Smoothed percentage body fat percentiles for U.S. children and adolescents, 1999-2004. Natl Health Stat Report 2011; 9: 1-7.

22. Kurtoglu S, Mazicioglu MM, Ozturk A, Hatipoglu N, Cicek B, Ustunbas HB. Body fat reference curves for healthy Turkish children and adolescents. Eur J Pediatr. 2010; 169:1329-35.

23. Eissa MA, Dai S, Mihalopoulos NL, Day RS, Harrist RB, Labarthe DR. Trajectories of fat mass index, fat free-mass index, and waist circumference in children: Project HeartBeat! Am J Prev Med 2009; 37 (Suppl. 1):S34-9.

24. Hattori K, Tahara Y, Moji K, Aoyagi K, Furusawa T. Chart analysis of body composition change among pre- and postadolescent Japanese subjects assessed by underwater weighing method. Int $\mathrm{J}$ Obes Relat Metab Disord 2004; 28:520-4.

25. Vasquez F, Salazar G, Diaz E, Lera L, Anziani A, Burrows R. Comparison of body fat calculations by sex and puberty status in obese schoolchildren using two and four compartment body composition models. Nutr Hosp. 2016; 33:1116-22.

26. Rodríguez G, Moreno LA, Blay MG, Blay VA, Fleta J, Sarría A, Bueno M; AVENA-Zaragoza Study Group. Body fat measurement in adolescents: comparison of skinfold thickness equations with dual-energy X-ray absorptiometry. Eur J Clin Nutr. 2005;59(10):1158-66.

\section{Figures}


Males Females

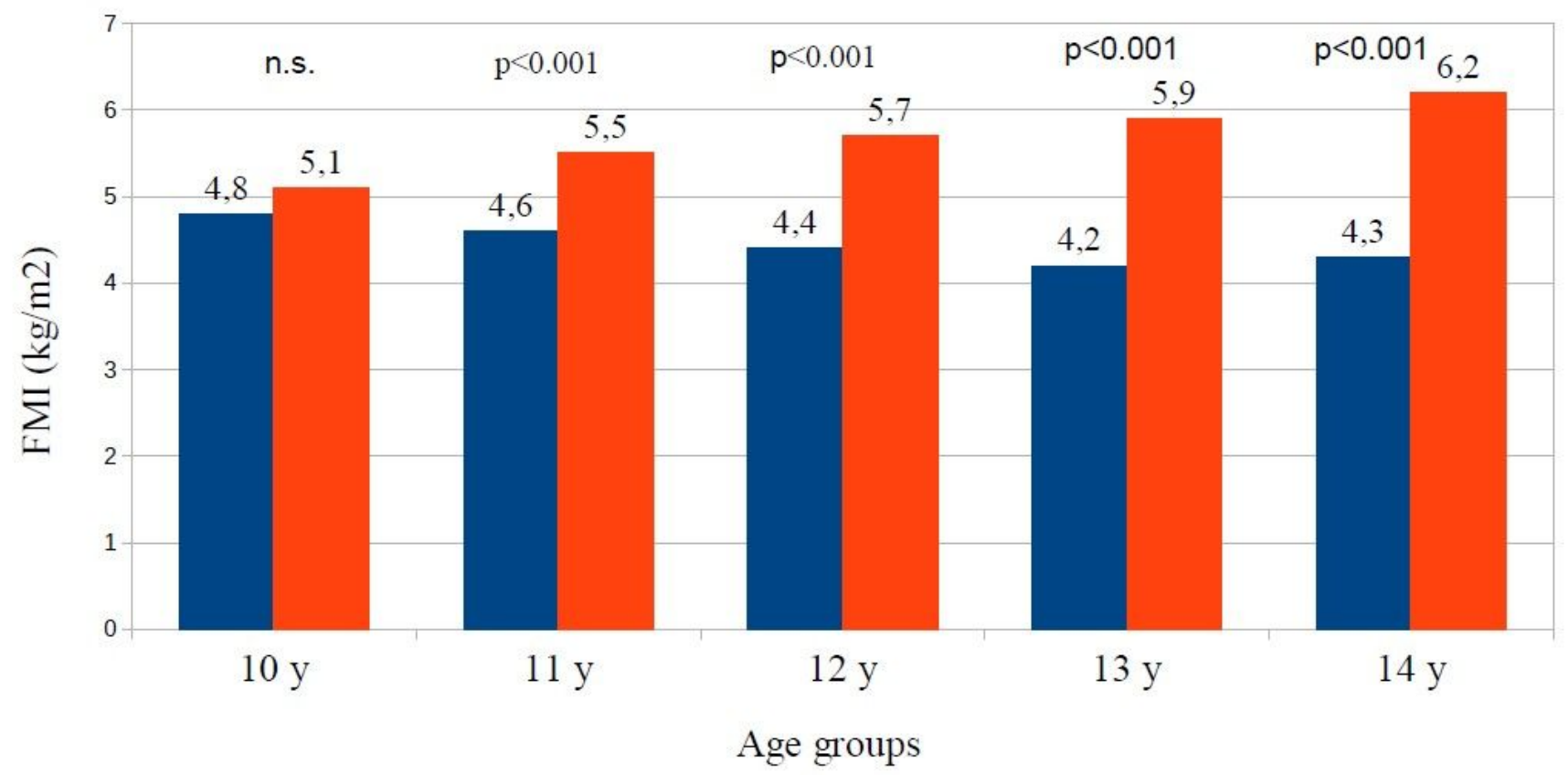

Figure 1

Gender differences for FMI in each of the ages. 
- Males Eemales

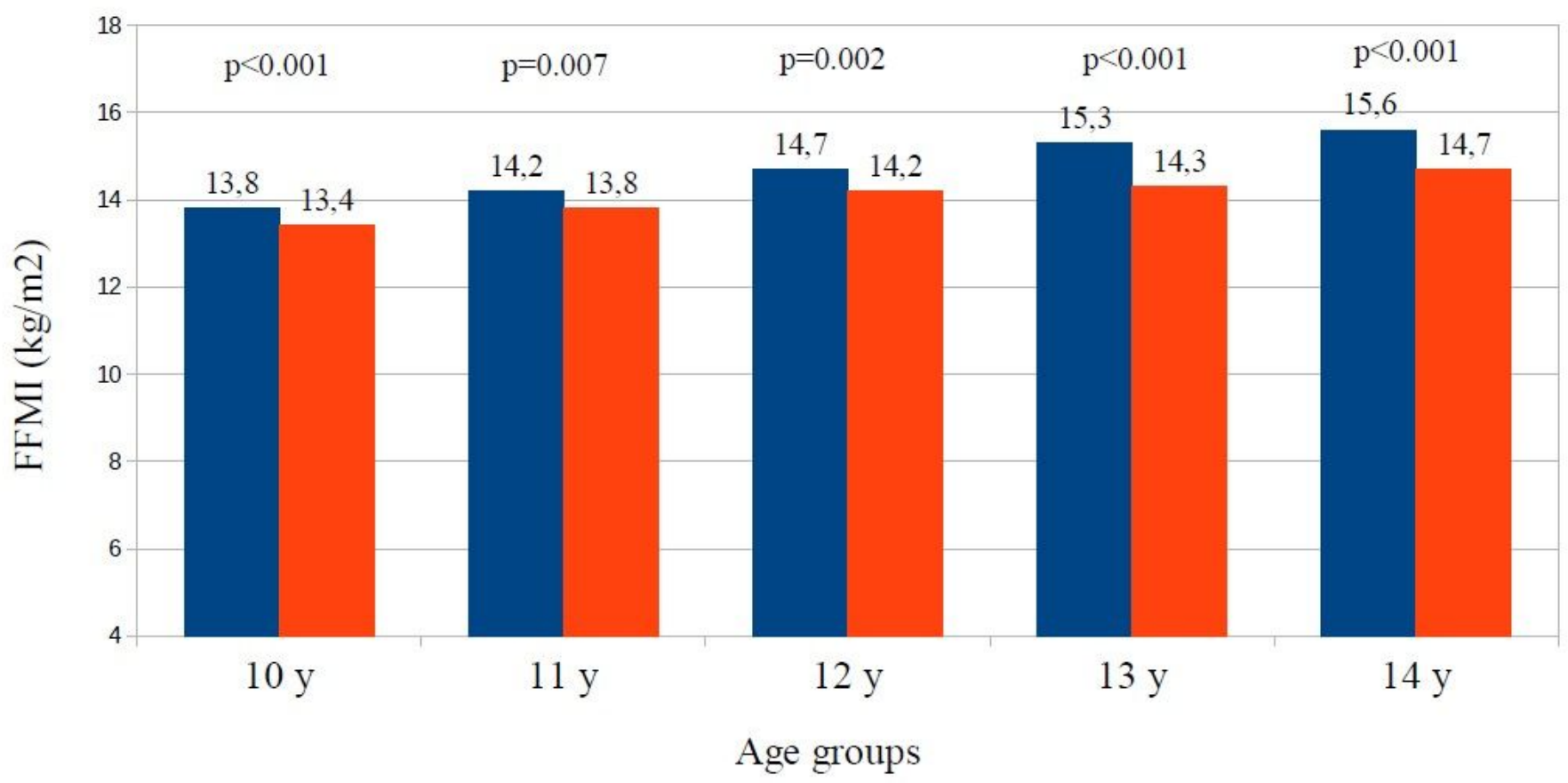

Figure 2

Gender differences for FFMI in each of the ages. 